Kummer, J. A., and E. M. Bayne. 2015. Bird feeders and their effects on bird-window collisions at residential houses. Avian Conservation and Ecology 10(2):6. http://dx.doi.org/10.5751/ACE-00787-100206

Copyright $(2015$ by the author(s). Published here under license by the Resilience Alliance.

Research Paper

\title{
Bird feeders and their effects on bird-window collisions at residential houses
}

\author{
Justine A. Kummer ${ }^{1}$ and Erin M. Bayne ${ }^{1}$ \\ ${ }^{1}$ Department of Biological Sciences, University of Alberta
}

\begin{abstract}
Feeding wild birds creates an important link between homeowners and conservation. The effects of bird feeders and year-round feeding on birds have not been well studied, however, particularly in relationship to bird-window collisions. We determined effects of bird feeder presence and placement on bird-window collisions at residential homes. Paired month-long trials in which a feeder was either present or absent for one month and then removed or added for the second month were completed at 55 windows at 43 houses. In each trial, homeowners were asked to search their study window daily for evidence of a bird-window collision. During the study there were 51 collisions when there was no bird feeder and 94 when the feeder was present. The season when each trial was set up was the best individual predictor of bird-window collisions. The largest number of collisions was observed during fall migration and the lowest during the winter months. There were no collisions at 26 of the study windows. High variance was observed in the number of collisions at different houses, indicating that effects of bird feeders are context dependent. Changing the occurrence, timing, and placement of feeders can alter collision rates but is only one of many factors that influence whether a residential house is likely to have a bird window-collision or not.
\end{abstract}

\section{Effets des mangeoires sur les collisions d'oiseaux avec les fenêtres de maisons}

RÉSUMÉ. Le fait de nourrir les oiseaux sauvages crée un lien important entre les propriétaires de maisons et la conservation. Toutefois, les effets des mangeoires sur les oiseaux et les effets de nourrir les oiseaux à l'année n'ont pas été approfondis, surtout en ce qui a trait aux collisions d'oiseaux avec les fenêtres. Nous avons déterminé les effets de la présence et de l'emplacement de mangeoires sur les collisions d'oiseaux avec les fenêtres de maisons. Des essais appariés d'une durée d'un mois, au cours desquels une mangeoire était soit présente soit absente pour le mois, puis était soit désinstallée soit installée pour le mois suivant, ont été réalisés à 55 fenêtres de 43 maisons. Lors de chaque essai, nous avons demandé aux propriétaires de vérifier quotidiennement la présence d'un indice de collision d'un oiseau avec la fenêtre à l'étude. Dans le cadre de cette recherche, 51 collisions avec une fenêtre sont survenues lorsqu'il n'y avait pas de mangeoires et 94 lorsqu'une mangeoire était installée. La saison de l'essai s'est révélée être la meilleure variable explicative des collisions d'oiseaux avec les fenêtres. Le plus grand nombre de collisions est survenu au cours de la migration automnale, tandis que le plus faible nombre a été observé durant les mois d'hiver. Aucune collision ne s'est produite à 26 fenêtres à l'étude. Nous avons obtenu une variance élevée du nombre de collisions à différentes maisons et ce résultat indique que les effets des mangeoires sont dépendants du contexte. Il est possible de modifier le moment de l'installation des mangeoires, la période durant laquelle celles-ci sont installées et leur emplacement afin de réduire le taux de collisions, mais cette possibilité ne représente qu'un facteur parmi de nombreux autres qui influent sur le fait qu'une maison sera susceptible d'entrainer des collisions d'oiseaux avec les fenêtres ou non.

Key Words: bird feeders; bird mortality; bird-window collisions; buildings; glass

\section{INTRODUCTION}

In an increasingly urbanized world, feeding birds creates a simple way for people to interact with wildlife (Goddard et al. 2013). The popularity of wild-bird feeding has increased considerably in the past few decades as homeowners have become progressively motivated to connect to the natural world as part of their daily lives (Fuller et al. 2008, Jones and Reynolds 2008, Robb et al. 2008, Goddard et al. 2013). In the United States, an estimated $43 \%-50 \%$ of households feed birds and up to $\$ 3.5$ billion is being spent annually on bird food and supplies (Jones and Reynolds 2008, Fuller et al. 2012). Despite the popularity of bird feeding, there has been little research to evaluate how it influences the ecology of wild birds at the individual, population, or community level (Jones 2011, Goddard et al. 2013).
Feeding wild birds has traditionally been encouraged to prevent malnourishment during harsh winters, thereby increasing overwinter survival (Brittingham 1990, Jones and Reynolds 2008). Organizations such as the British Trust for Ornithology, the Royal Society for the Protection of Birds, and the Cornell Lab of Ornithology have actively encouraged wild-bird feeding as an activity to promote conservation. More recently, many of these groups have endorsed year-round feeding as both appropriate and beneficial under the assumption that it enhances breeding success (Robb et al. 2008). However, the overall benefit of feeding has not been evaluated relative to potential liabilities. Concerns about behavioral changes caused by feeder dependency as well as reduced survival caused by increased predator attraction, disease spread, and collisions with human infrastructure have been raised (Jones 2011, Davies et al. 2012). 
In the most recent bird-window collision estimate for Canada, $90 \%$ of all window collision mortality was estimated to occur with residential windows (Machtans et al. 2013). Considerable variation exists between different types of residences in collision rates (Bayne et al. 2012), and a growing number of researchers are trying to identify what makes one home more or less likely to incur a bird-window collision (Dunn 1993, Klem et al. 2004, Bayne et al. 2012, Hager et al. 2013). The use of bird feeders and where feeders are placed relative to windows is an area of increasing focus. Dunn (1993) conducted a North American survey of homes with bird feeders and found the abundance of species that commonly use feeders increased with bird feeding and that abundance of these species was a good predictor of birdwindow collisions. As a result, those species most likely to be window collision victims were those that frequented bird feeders. Bayne et al. (2012) found a similar pattern, whereby bird-window collisions were reported as being more common when a bird feeder was present. However, there was no relationship drawn between reported collisions and the species of birds that frequent feeders. In contrast, Hager et al. (2013) found a strong positive relationship between bird feeder presence and abundance of common bird feeder species, but not between bird feeders and bird-window collisions. Based on these somewhat conflicting results, more work is needed to better understand the relationship between birdwindow collisions and bird feeders.

The window collision mitigation strategies most commonly recommended when using bird feeders are based on the results of one study that manipulated the distance of feeders relative to windows (Klem et al. 2004). This study, along with the majority of past studies exploring effects of bird feeders, have been done in woodlands and at scientific field stations (Orros and Fellowes 2012). For example, Klem et al. (2004) placed a series of window panes and bird feeders along the edge of a mixed deciduous forest and open field. There was an increase in the number of birdwindow collisions when feeders were placed 2-10 $\mathrm{m}$ from a window. Within $1 \mathrm{~m}$, birds were drawn to the feeder but because of its proximity to the window pane, fewer birds hit windows and fewer mortalities occurred because birds were unable to build up enough momentum to sustain serious injury if they hit the glass upon departure (Klem et al. 2004). These results are frequently used as evidence that placing bird feeders close to a window is a safe urban bird feeding practice. There have been no scientific studies, however, that look at effects of bird feeders at different distances on bird-window collisions in actual residential settings.

Our objective was to determine if bird feeder presence and placement influenced bird-window collisions at residential homes. We predicted that when feeders were present more birds would collide with windows because birds would be attracted to those residences. Fewer collisions were expected when feeders were placed close to versus far from windows based on flight speed and awareness of the window when leaving a feeder that was closer to the window. The general public are unlikely to stop feeding birds and there are a number of accepted benefits in them continuing. Thus, continuing to learn about the relationship between bird feeders and bird-window collisions is important in identifying ways homeowners can safely feed birds, while reducing bird-window collision risk at their home.

\section{METHODS}

\section{Site selection}

Houses for this experiment were identified using a variety of methods. Homeowners who had previously registered for our Birds and Windows Project (http://birdswindows.biology. ualberta.ca/) were contacted and asked to participate in the study. Homeowners were also recruited through personal contact and social media (Facebook and Twitter accounts), and by delivering pamphlets and putting up posters in residential neighborhoods in Edmonton. The bird feeder experiment was a focus of three Canadian Broadcasting Corporation Radio interviews and was featured on Canadian Broadcasting Corporation Alberta Late Night News. Emails were sent across Edmonton to community leagues, schools, and established nature and bird organizations. In total, 43 houses were recruited within Edmonton, Alberta, and the surrounding area for our bird feeder experiment.

In selecting a window at each house, we allowed homeowners to indicate their preference and the one they felt was most likely to receive a collision. Other factors we considered when selecting a window included window size, presence of an already existing bird feeder, and nearby vegetation. Large windows with a bird feeder already present, shrubs or trees in close proximity, and a history of collisions were preferred but not essential in choosing a window. At 12 houses, 2 different windows were evaluated during different trials. A greenhouse and 2 clear deck railings were chosen instead of a window at 3 houses. The experiment was completed at a total of 55 windows at 43 houses.

One bird feeder was placed $1 \mathrm{~m}(\mathrm{n}=103)$ or $5 \mathrm{~m}(\mathrm{n}=39)$ in front of the selected window at each home during a trial. The presence of trees or large vegetation sometimes limited feeder placement, and both distances could not be evaluated at each house. Additionally, some homeowners requested the bird feeder remain off their lawn, limiting the distances that could be tested at each home.

Bird feeders sat atop wooden stands that were anchored into the ground. They were placed at a height approximately in the middle of each window. Each bird feeder was gazebo style with a perch and attached roof. Feeders were filled with black oil sunflower seeds. Homeowners were instructed to keep the feeder full, and when requested they were provided with their own seed or we visited and refilled the feeder.

\section{Experimental design}

The study was conducted from April 2014 to May 2015. The basic design consisted of a series of paired month-long trials. In the first month, a feeder was either present or absent for that month and then removed or added for the second month. The order of each month was randomized, and each trial lasted approximately 31 days. In total there were 284 completed trials. After each pair of trials, homeowners were given a break lasting at least 1 week (length varied among homeowners) before another set of trials began. At each window, one $(n=11)$, two $(n=15)$, three $(n=15)$, or four $(n=14)$ paired trials were completed by the homeowner over the study period.

Homeowners searched their study window every day for evidence of a window collision. Forms of evidence included a dead or 
injured bird, a body smudge, feathers or blood on the window, and hearing or seeing a collision occur. If the homeowner reported any one form of evidence it was counted as a collision. Participants had the option of entering their observations into the Birds and Windows online database or to fill out paper data sheets.

\section{Data analysis}

After each trial, homeowners were asked to confirm each window collision recorded, and all observations were checked for consistency. From homeowner observations we calculated the total number of collisions with and without a feeder pooled for all houses (hereafter POOLED), the total number of collisions with and without a feeder occurring at each house pooled across all trials at that house (hereafter HOUSE), and the total number of collisions occurring per trial at each window (hereafter TRIAL).

A chi-square test was used to determine if there was a difference in the total number of collisions POOLED when a bird feeder was present and when a bird feeder was absent. A multilevel mixed-effects count model was used to determine if the total number of collisions at each HOUSE differed according to the presence or absence of the feeder, while controlling for the number of trials done at each house (command menbreg in Stata 13; StataCorp, College Station, Texas, USA, http://www.stata.com/). Finally, a multilevel mixed-effects count model was used to determine the rate of bird-window collisions accounting for seasonal, house, and window attributes based on each TRIAL. Each analysis was run using all species and again after removing collisions by species that do not eat seeds and do not regularly frequent bird feeders, i.e., Cedar Waxwings (Bombycilla cedrorum), Bohemian Waxwings (Bombycilla garrulus), and American Robins (Turdus migratorius).

For the multilevel mixed-effects count model at the TRIAL level, various fixed and random effects were added and compared using Akaike's information criterion (AIC; Burnham and Anderson 2004), as well as likelihood ratio tests to determine the best model structure and evaluate how bird feeder presence and feeder location influenced the number of collisions. We compared how model fit changed when we included fixed effects for (1) presence/ absence of a feeder as a categorical variable (hereafter FEEDER); (2) absence of a feeder or whether a feeder was present at $1 \mathrm{~m}$ or $5 \mathrm{~m}$ from the window as a categorical variable (hereafter DISTANCE); (3) time of year the trial started as a categorical variable with four levels: spring migration, summer breeding, fall migration, and winter (hereafter SEASON); (4) SEASON + FEEDER; (5) SEASON + DISTANCE; and (6) SEASON * FEEDER. Based on personal experience related to migration of birds in Edmonton, we defined winter as being the period between 15 October and 14 March, spring migration being 15 March to 14 May, summer breeding being 15 May to 14 August, and fall migration being 15 August to 14 October. In preliminary analyses, we looked at the month of the year the trial began as an alternative variable for season, but there were no reported collisions in December and February so we could not achieve model convergence. We also tried to evaluate the interaction between SEASON * DISTANCE, but there were an insufficient number of collisions in the winter to allow model convergence.

\section{RESULTS}

Throughout the experiment there were 145 bird-window collisions. The mea number of collisions per trial was 0.51 (SD 1.47). There were no collisions reported in 223 of the 284 trials. There were 5 collisions at one clear deck railing but no collisions at the other deck railing or the greenhouse.

Of the 145 birds that collided, 89 survived the event. There were only 11 reported fatalities and the fate of 45 birds was unknown. When the bird feeder was present, there were only $7(7.5 \%)$ fatalities and $55(58.5 \%)$ birds survived the collision. These percentages are comparable to those observed when there was no bird feeder present (7.8\% died and 66.7\% survived). Species could be identified in 35 of the observed bird-window collisions by our citizen scientists (Table 1). Another 15 birds were identified to broader groupings. Based on personal experience with the urban bird community and educated guesses, we identified the 5 chickadees as Black-capped Chickadees (Poecile atricapillus) and the woodpecker and 2 waxwings as a Downy Woodpecker (Picoides pubescens) and Cedar waxwings, respectively. There are several different sparrow species in the Edmonton area, and as a result the 7 sparrows could not be classified further. Together, Black-capped Chickadees $(\mathrm{n}=12)$, House Sparrows (Passer domesticus; $\mathrm{n}=7$ ), and Dark-eyed Juncos (Junco hyemalis; $\mathrm{n}=4$ ) composed almost half of the identified species colliding with windows. Other prominent species included nonfeeder species such as American Robins $(n=6)$ and Cedar and Bohemian waxwings $(n=8)$.

Table 1. Percentage of reported collisions and the sample size for each species that collided.

\begin{tabular}{lcc}
\hline \hline Species & \% Collided & Sample size $(n)$ \\
\hline $\begin{array}{l}\text { American Robin (Turdus } \\
\text { migratorius) }\end{array}$ & 4.14 & 6 \\
$\begin{array}{l}\text { Black-capped Chickadee (Poecile } \\
\text { atricapillus) }\end{array}$ & 8.28 & 12 \\
$\begin{array}{l}\text { Blue Jay (Cyanocitta cristata) } \\
\text { Bohemian Waxwing (Bombycilla } \\
\text { garrulus) }\end{array}$ & 0.69 & 1 \\
$\begin{array}{l}\text { Cedar Waxwing (Bombycilla } \\
\text { cedrorum) }\end{array}$ & 0.69 & 1 \\
$\begin{array}{l}\text { Dark-eyed Junco (Junco } \\
\text { hyemalis) }\end{array}$ & 4.83 & 7 \\
$\begin{array}{l}\text { Downy Woodpecker (Picoides } \\
\text { pubescens) }\end{array}$ & 1.38 & 4 \\
$\begin{array}{l}\text { House Sparrow (Passer } \\
\text { domesticus) }\end{array}$ & 4.83 & 2 \\
$\begin{array}{l}\text { Purple Finch (Haemorhous } \\
\text { purpureus) }\end{array}$ & 0.69 & 7 \\
$\begin{array}{l}\text { Red-breasted Nuthatch (Sitta } \\
\text { canadensis) }\end{array}$ & 0.69 & 1 \\
$\begin{array}{l}\text { Sparrow sp. } \\
\text { Swainson's Thrush (Catharus } \\
\text { ustulatus) }\end{array}$ & 4.83 & 7 \\
Unknown & 0.69 & 1 \\
\hline
\end{tabular}

There were 51 collisions, with a mean of 0.36 (SD 0.93) per trial when there was no bird feeder present. When a feeder was added, the number of collisions increased to 94 with a mean of 0.66 (SD 1.86) per trial (Fig. 1). There were significantly more POOLED 
collisions when a bird feeder was present $\left(\chi^{2}=12.2\right.$, df $=1, P=$ 0.005). The presence of a bird feeder increased the collision rate 1.84 times. Excluding collisions by waxwings and robins dropped the number of collisions when there was a feeder to 90 and when there was not a feeder to 41 . There were again significantly more collisions when a feeder was present $\left(\chi^{2}=17.6, \mathrm{df}=1, \mathrm{P}<0.001\right)$, and the collision rate was increased 2.20 times when a feeder was present versus absent.

Fig. 1. Histogram showing percentage of residences reporting a particular number of bird-window collisions during trials with no feeder and trials where the bird feeder was present in front of the window.
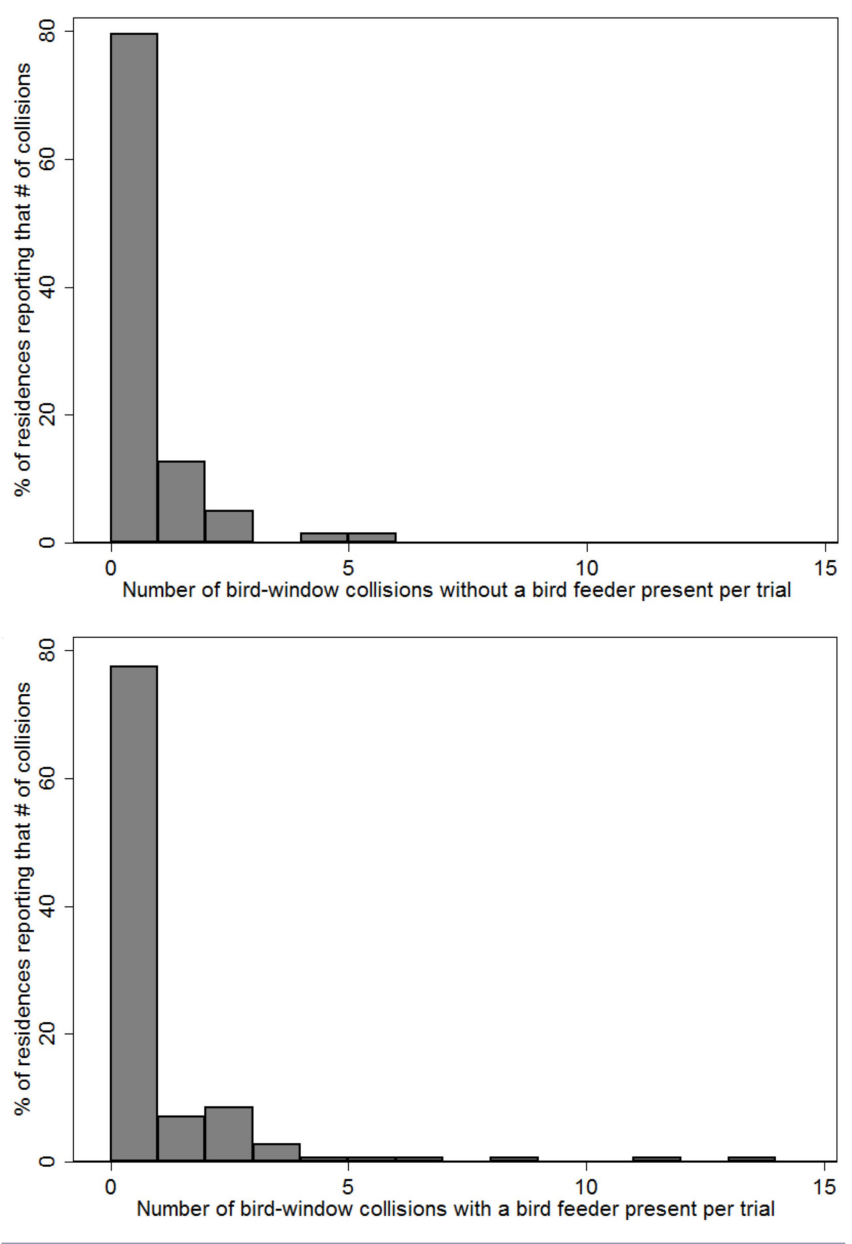

Based on AIC in our most complex model, a model based on a negative binomial distribution provided a much better fit than one based on a Poisson distribution for HOUSE-level collisions (Poisson AIC $=288.26$, negative binomial $\mathrm{AIC}=276.40$ ). Including HOUSE as a random effect resulted in significant model improvement relative to a standard negative binomial regression $\left(\chi^{2}=14.5, P<0.001\right)$. For the number of collisions at the HOUSE level, bird feeder presence increased the collision rate 1.57 times $\left(\chi^{2}=2.4, P=0.12\right)$. The collision rate increased 1.81 times $\left(\chi^{2}=4.0, P=0.05\right)$ when robin and waxwing collisions were removed.
Comparing each house in its back-to-back trials (feeder vs. no feeder) at each window, we found 10 houses had a greater number of reported collisions when no feeder was present and 14 houses had more collisions when a bird feeder was present $(\mathrm{t}=1.3 \mathrm{df}=$ $84, \mathrm{P}=0.19$ ). There were no collisions reported at 18 houses, and 1 house had the same number of collisions reported both when a feeder was present and when a feeder was absent. The top 5 houses reported $25,19,17,15$, and 9 collisions while participating in the project.

Based on the AIC in our most complex model, negative binomial distribution $(\mathrm{AIC}=463.37)$ provided a much better fit than Poisson (AIC $=495.66$ ) for TRIAL-level collisions. With no fixed effects in the model, we evaluated whether individual house and study window within each house treated as nested or individual random effects provided a better fit. Including the individual window as a single random effect provided a better fit than treating house as a random effect or nesting window within house based on AIC ( $\triangle \mathrm{AIC}$ of more than 2 with window providing a better fit relative to the nested model or the model with house identity as a random effect). Including window as a random effect resulted in significant model improvement relative to a standard negative binomial regression $\left(\chi^{2}=15.7, \mathrm{P}<0.001\right)$.

In predicting TRIAL-level collision rate, bird feeder presence was a better predictor than bird feeder distance from the window when included as a single fixed effect (Table 2). When the feeder was 1 $\mathrm{m}$ from the window, the total number of collisions was 66 , with a mean of 0.64 (SD 1.82) per trial. At $5 \mathrm{~m}$ there were fewer trials so the total number of collisions was only 28 , but the mean number of collisions was higher at 0.72 (SD 1.99) per trial.

Based on the AIC, the best model with a single fixed effect was SEASON, with far fewer collisions occurring in the winter. There was a mean of 0.11 (SD 0.40) collisions in the winter, and this increased to 0.79 (SD 1.52) during spring migration, 0.54 (SD 1.36 ) in the summer breeding months, and 1.08 (SD 2.66) through fall migration (Table 2, Fig. 2).

Fig. 2. Bar graph showing the mean number of bird-window collisions for each season: winter $(\mathrm{n}=92)$, spring migration $(\mathrm{n}$ $=39)$, summer breeding $(n=40)$, and fall migration $(n=40)$. The mean number of collisions was calculated for each season and subdivided for trials with no bird feeder (NO) and trials with a bird feeder present (YES).

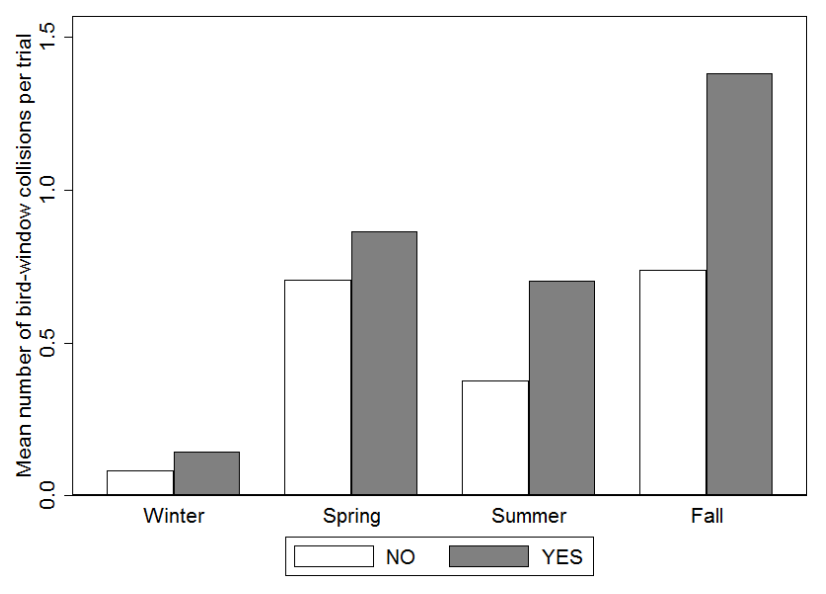


Table 2. Akaike information criterion (AIC) scores for each model looking at the factors affecting bird-window collisions at residential houses. Summary also includes the relative difference between models and the best model( $\triangle$ AIC), Akaike weights (AICw), log-likelihood $(\mathrm{L})$, and number of parameters $(\mathrm{K})$. All tests were run twice: once with all reported collisions and again after removing collisions from Cedar Waxwings (Bombycilla cedrorum), Bohemian Waxwings (Bombycilla garrulus), and American Robins (Turdus migratorius).

\begin{tabular}{|c|c|c|c|c|c|}
\hline Model & $\mathrm{AIC}$ & $\Delta \mathrm{AIC}$ & $\mathrm{AICw}$ & $L$ & $\mathrm{~K}$ \\
\hline \multicolumn{6}{|l|}{ All birds } \\
\hline SEASON + FEEDER & 463.37 & 0.00 & 0.44 & -224.69 & 7 \\
\hline SEASON & 464.04 & 0.67 & 0.32 & -226.02 & 6 \\
\hline SEASON + DISTANCE & 465.30 & 1.93 & 0.17 & -224.65 & 8 \\
\hline SEASON * FEEDER & 467.00 & 3.63 & 0.07 & -223.50 & 10 \\
\hline FEEDER & 478.68 & 15.31 & 0.00 & -235.34 & 4 \\
\hline DISTANCE & 480.66 & 17.29 & 0.00 & -235.33 & 5 \\
\hline WINDOW & 479.70 & 16.33 & 0.00 & -236.85 & 3 \\
\hline NULL & 493.40 & 30.03 & 0.00 & -244.70 & 2 \\
\hline \multicolumn{6}{|l|}{ Feeder birds only } \\
\hline SEASON + FEEDER & 435.18 & 0.00 & 0.55 & -210.59 & 7 \\
\hline SEASON + DISTANCE & 436.84 & 1.66 & 0.24 & -210.42 & 8 \\
\hline SEASON & 437.51 & 2.33 & 0.17 & -212.76 & 6 \\
\hline SEASON * FEEDER & 440.53 & 5.35 & 0.04 & -210.27 & 10 \\
\hline FEEDER & 447.14 & 11.96 & 0.00 & -219.57 & 4 \\
\hline DISTANCE & 448.93 & 13.75 & 0.00 & -219.47 & 5 \\
\hline WINDOW & 449.95 & 14.77 & 0.00 & -221.97 & 3 \\
\hline NULL & 464.94 & 29.76 & 0.00 & -230.47 & 2 \\
\hline
\end{tabular}

The best-fitting model was SEASON + FEEDER. Adding FEEDER to the SEASON model improved model fit only slightly, with a $\triangle$ AIC of 0.67. SEASON + FEEDER had more support than SEASON + DISTANCE and SEASON * FEEDER (Table 2). When FEEDER was modeled as a single fixed effect, the increase in number of collisions was 1.69 times higher $\left(\chi^{2}=\right.$ $3.1, \mathrm{P}=0.08$ ) when feeders were present. After accounting for SEASON, the collision rate was 1.59 times higher when feeders were present $\left(\chi^{2}=3.3, P=0.07\right)$. When the species that do not frequent feeders were removed, SEASON + FEEDER remained the best model based on AIC (Table 2). The collision rate with FEEDER as a single fixed effect was $1.96\left(\chi^{2}=4.9, \mathrm{P}=0.03\right)$ in the presence of a bird feeder. When SEASON was included, there were 1.83 times more collisions $\left(\chi^{2}=5.3, \mathrm{P}=0.02\right)$.

\section{DISCUSSION}

This is the first manipulative experiment to look at the relationship between bird feeders and bird-window collisions in a residential setting. In our study, bird feeder presence increased collision risk 1.57 to 2.20 times, depending on the model, relative to not having a feeder. Admittedly, our mixed-model results using all reported collisions were not statistically significant at $\mathrm{P}=0.05$ or at $\triangle \mathrm{AIC}$ $>2$, suggesting that bird feeder presence was a weak predictor of collision rate after accounting for house and window attributes. However, effect size in our manipulative experiment was similar to that in other correlative studies that demonstrated statistically significant results because of larger sample sizes. For example, Bayne et al. (2012) found that people with feeders remembered 1.82 and 2.62 times more collisions occurring at their homes in two different years than people who did not have feeders. In a comparable study, where homeowners actively searched around their home for collisions, urban houses with a feeder had 1.98 more collisions than houses without (J. A. Kummer, E. M. Bayne, and C.S. Machtans, unpublishedmanuscript). Overall, houses with bird feeders consistently report more bird-window collisions that those without, regardless of how collision data have been collected (Klem et al. 2004, Bayne et al. 2012; J. A. Kummer, E. M. Bayne, and C. S. Machtans, unpublished manuscript).

All our models were improved and became statistically significant at $\mathrm{P}=0.05$ once collisions by nonfeeder bird species were removed. Across our models there was an increased risk of a collision for feeder species in the presence of a bird feeder. This suggests that effects of bird feeder presence on collision risk are specific to species that frequently visit bird feeders. Future studies should attempt to determine which species of birds using feeders are at greatest risk of collisions, but this will require far larger sample sizes than we were able to achieve.

Although the average collision rate we observed was consistent with that in previous studies, we found very high variance in the number of collisions between different houses. This variance between houses drove the differences between the cumulative total and mixed-effects results. Almost half of the houses reported no collisions, yet there was one window at one house where bird feeder presence increased the collision rate by more than 11 times. This trend was not seen at each of the homes reporting high collision numbers. The house where 15 collisions were reported saw almost 3 times as many collisions when there was no feeder than when there was a feeder present. A similar number of collisions for each treatment was also observed at some houses that reported a high number of collisions. This suggests that the effects of a bird feeder are dependent on the house and window. Overall, some houses have a much higher risk than others, suggesting that impacts of feeding birds may be context dependent.

Klem et al. (2004) recommend placing bird feeders closer to windows to reduce collisions and/or their severity for birds. Similar to Klem et al. (2004), we had a slightly higher collision rate when feeder distance was $5 \mathrm{~m}$ compared with $1 \mathrm{~m}$, but there was not strong statistical support for this difference being 
important. Admittedly, there were fewer trials in the 5-m distance class because of constraints on our design related to homeowner preferences and yard configuration. It is likely that variability in bird-window collisions limits our ability to detect subtle differences as a result of bird feeder distance from a window. Thus, although we cannot dismiss the recommendation that placing feeders closer to windows will reduce collisions and/or their severity, our results do not strongly support this.

Seasonality was the most important driver of bird-window collision rate. Bird-window collisions are affected by seasonality, yet prior to this study no complete continuous data set looked at bird-window collision trends over an entire year (Klem 1989, Codoner 1995, Bayne et al. 2012, Hager et al. 2013). The few collisions observed during the winter months is not surprising for Alberta because more than $80 \%$ of the bird species in Alberta are migratory (Bayne et al. 2012, Hager et al. 2013). There was an additional decline in the number of collisions during the early summer months. Klem (1989) also reported fewer collisions at this time because breeding birds seem to be moving less. The collision spikes that occurred during the spring, late summer, and early fall coincide with migration. Edmonton is located within three migratory flyways and as a result, a large number of birds fly through and stop in the region during their spring and fall migration (City of Edmonton 2008). The increased abundance of birds at these times presumably leads to a greater risk of window collisions because more birds are being drawn towards windows (Dunn 1993, Hager et al. 2013). We had insufficient data to explicitly test if feeders have a differential effect at certain times of the year, and this is an area that warrants further investigation.

It has previously been shown that there is an increase in the abundance of birds that frequent feeders when a bird feeder is present (Dunn 1993, Fuller et al. 2008). If this increased abundance increases collision risk, as suggested by Dunn (1993), it is not surprising that the majority of species we saw collide with windows were those that use feeders. However, there were a number of nonfeeder species that collided. A number of houses that participated had a bird feeder in their yard before the study, and as proposed by Dunn (1993), such homes are often characterized by abundant green space and are attractive to both feeder and nonfeeder species. There were few fatalities during the study, and it is possible the resident species that frequent feeders year-round may be more aware of windows. In addition, although resident species increase their feeder use in the winter (Chamberlain et al. 2005), they may no longer have green vegetation reflected in windows to the same degree at this time, reducing their collision risk relative to migrant species. Yearround feeding has been promoted and encouraged to promote conservation, but depending on the home and feeder placement, feeding only during the winter months might be more beneficial to populations and help reduce collisions. Ultimately, detailed demographic studies at appropriate scales are required to assess the benefits that feeding has for birds to determine if the benefits to individual health and reproductive success compensate for increased mortality associated with window collisions.

In conducting our study, we were unable to validate homeowner observations. Bird-window collisions are a quick event. Thus, it is possible that more collisions occurred than were recorded throughout the experiment (Smallwood 2007, Hager et al. 2012, Machtans et al. 2013, Loss et al. 2014). At the start of the study, we attempted to use remote cameras and motion capture to photograph collisions at all of the windows used in this study. This was not effective because our cameras were not fast enough to detect collision events and get a high-quality photo. Future work in this area should use high-speed video that runs continuously to validate homeowner observations and confirm that collision rates estimated by a single visit per day are in fact accurate. Alternatively, there are now security devices available that can sense vibrations when they occur at windows. This could be particularly important for collisions occurring when the feeder is placed $1 \mathrm{~m}$ from the window because birds may not gather enough momentum to leave visible evidence of a collision. Given the magnitude of bird-window collisions in North America and the potential effects they are having on bird populations (Machtans et al. 2013, Loss et al. 2014), more investment in monitoring technology that will allow us to accurately test the efficacy of mitigation approaches for bird-window collisions is needed.

By conducting this study at actual houses, our results suggest homeowners can mitigate some bird-window collisions by removing bird feeders. Feeders are one of many factors that influence whether a residence is likely to have a large number of collisions (Bayne et al. 2012). Types of glass, proximity to highquality bird habitat, window decals, and local vegetation are other factors that need to be tested more fully to assess what the most cost-effective way is to mitigate bird-window collisions. We cannot refute the argument made by Klem et al. (2004) that if a feeder is going to be placed in front of a window it should be placed close to that window. Trials testing the placement of bird feeders at different angles from windows should also be completed to see how eliminating the direct line of sight to the window affects the number of collisions.

Eliminating bird feeders will not solve the bird-window collision issue. Bird feeders do play a role in collisions, but they are context dependent. In working towards eliminating bird-window collisions a combination of factors will need to be considered (Robb et al. 2008). Homeowners are not particularly interested in getting better estimates of the severity of bird-window collisions. Instead, they take pride in their yard and the birds in it. They want to know how to feed the birds in their yard safely. Feeding wild birds creates an important link between the general public and nature, and improving this relationship will continue to promote biodiversity and conservation. In conducting this study a number of participants provided updates on the activity at their bird feeder, and at the end of the project a handful kept their feeder. Homeowners enjoy having birds in their yards and being able to feed them. Finding successful ways for them to do so could be beneficial to both birds and the millions of people who feed them. More effort is required by ornithologists to assess how this might be done.

Responses to this article can be read online at: http://www.ace-eco.org/issues/responses.php/787

\section{Acknowledgments:}

We want to thank the 43 families who allowed us to place bird feeders at their home during the course of the study. Their continued dedication in searching for bird-window collision evidence every day 
was greatly appreciated. This project would not have been a success without them. We also want to thank B. Kummer, A. Menzies, and M. Xia for their help with project setup. The Department of Biological Sciences at the University of Alberta and Environment Canada provided funding for the project. This research was conducted under permits \#Pro000413111 and \#AUP00001361 from the Research Ethics Board at the University of Alberta.

\section{LITERATURE CITED}

Bayne, E. M., C. A. Scobie, and M. Rawson-Clark. 2012. Factors influencing the annual risk of bird-window collisions at residential structures in Alberta, Canada. Wildlife Research 39:583-592. http://dx.doi.org/10.1071/WR11179

Brittingham, M. C. 1991. Effects of winter bird feeding on wild birds. Pages 185-190 in L. W. Adams and D. L. Leedy, editors. Wildlife conservation in metropolitian environments. National Institute for Urban Wildlife, Columbia, Maryland, USA.

Burnham, K. P., and D. R. Anderson. 2004. Multimodel inference: understanding AIC and BIC in model selection. Sociological Methods \& Research 33:261-304. http://dx.doi. org/10.1177/0049124104268644

Chamberlain, D. E., J. A. Vickery, D. E. Glue, R. A. Robinson, G. J. Conway, R. J. W. Woodburn, and A. R. Cannon. 2005. Annual and seasonal trends in the use of garden feeders by birds in winter. Ibis 147:563-575. http://dx.doi.org/10.1111/ j.1474-919x.2005.00430.x

City of Edmonton. 2008. Biodiversity report. Local Action for Biodiversity (LAB) Project. Edmonton, Alberta, Canada. [online] URL: http://www.edmonton.ca/city_government/documents/ PDF/BIO_DIVERSITY_REPORT_-_high_res_August2008.pdf

Codoner, N. A. 1995. Mortality of Connecticut birds on roads and at buildings. Connecticut Warbler 15:89-98.

Davies, Z. G., R. A. Fuller, M. Dallimer, A. Loram, and K. J. Gaston. 2012. Household factors influencing participation in bird feeding activity: a national scale analysis. PLoS ONE 7(6):e39692. http://dx.doi.org/doi:10.1371/journal.pone.0039692 http://dx.doi. org/10.1371/journal.pone.0039692

Dunn, E. H. 1993. Bird mortality from striking residential windows in winter. Journal of Field Ornithology 64:302-309.

Fuller, R. A., K. N. Irvine, Z. G. Davies, P. R. Armsworth, and K. J. Gaston. 2012. Interactions between people and birds in urban landscapes. Pages 249-266 in C. A. Lepczyk and P. S. Warren, editors. Urban bird ecology and conservation. Studies in avian biology (no. 45). University of California Press, Berkeley, California, USA. http://dx.doi.org/10.1525/california/9780520273092.003 .0016

Fuller, R. A., P. H. Warren, P. R. Armsworth, O. Barbosa, and K. J. Gaston. 2008. Garden bird feeding predicts the structure of urban avian assemblages. Diversity and Distributions 14:131-137. http://dx.doi.org/10.1111/j.1472-4642.2007.00439.x
Goddard, M. A., A. J. Dougill, and T. G. Benton. 2013. Why garden for wildlife? Social and ecological drivers, motivations and barriers for biodiversity management in residential landscapes. Ecological Economics 86:258-273. http://dx.doi.org/10.1016/j. ecolecon.2012.07.016

Hager, S. B., B. J. Cosentino, and K. J. McKay. 2012. Scavenging affects persistence of avian carcasses resulting from window collisions in an urban landscape. Journal of Field Ornithology 83:203-211. http://dx.doi.org/10.1111/j.1557-9263.2012.00370.x

Hager, S. B., B. J. Cosentino, K. J. McKay, C. Monson, W. Zuurdeeg, and B. Blevins. 2013. Window area and development drive spatial variation in bird-window collisions in an urban landscape. PLoS ONE 8(1):e53371. http://dx.doi.org/10.1371/ journal.pone.0053371

Jones, D. 2011. An appetite for connection: why we need to understand the effect and value of feeding wild birds. Emu 111:1-7. http://dx.doi.org/10.1071/MUv111n2_ED

Jones, D. N., and S. J. Reynolds. 2008. Feeding birds in our towns and cities: a global research opportunity. Journal of Avian Biology 39:265-271. http://dx.doi.org/10.1111/j.0908-8857.2008.04271.x

Klem, D. 1989. Bird-window collisions. Wilson Bulletin 101:606-620.

Klem, D., Jr., D. C. Keck, K. L. Marty, A. J. Miller Ball, E. E. Niciu, and C. T. Platt. 2004. Effects of window angling, feeder placement, and scavengers on avian mortality at plate glass. Wilson Bulletin 116:69-73. http://dx.doi.org/10.1676/0043-5643 (2004)116[0069:EOWAFP]2.0.CO;2

Loss, S. R., T. Wil, S. S. Loss, and P. P. Marra. 2014. Bird-building collisions in the United States: estimates of annual mortality and species vulnerability. Condor 116(1):8-23. http://dx.doi. org/10.1650/condor-13-090.1

Machtans, C. S., C. H. R. Wedeles, and E. M. Bayne. 2013. A first estimate for Canada of the number of birds killed by colliding with building windows. Avian Conservation and Ecology 8(2):6. http://dx.doi.org/10.5751/ACE-00568-080206

Orros, M. E., and M. D. E. Fellowes. 2012. Supplementary feeding of wild birds indirectly affects the local abundance of arthropod prey. Basic and Applied Ecology 13:286-293. http://dx.doi. org/10.1016/j.baae.2012.03.001

Robb, G. N., R. A. McDonald, D. E. Chamberlain, and S. Bearhop. 2008. Food for thought: supplementary feeding as a driver of ecological change in avian populations. Frontiers in Ecology and the Environment 6:476-484. http://dx.doi. org/10.1890/060152

Smallwood, K. S. 2007. Estimating wind turbine-caused bird mortality. Journal of Wildlife Management 71:2781-2791. http:// dx.doi.org/10.2193/2007-006
Editor-in-Chief: Ryan Norris Subject Editor: Dave Shutler

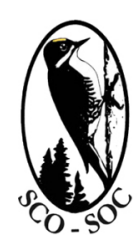

Sponsored by the Society of Canadian Ornithologists and Bird Studies Canada Parrainée par la Société des ornithologistes du Canada et Etudes d'oiseaux Canada

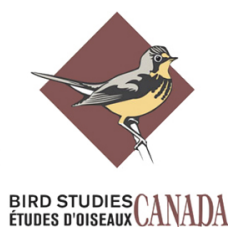

